\title{
Defining Medical Futility and Improving Medical Care
}

\author{
Lawrence J. Schneiderman
}

Received: 10 November 2010 / Accepted: 12 January 2011 / Published online: 20 March 2011

(C) The Author(s) 2011. This article is published with open access at Springerlink.com

\begin{abstract}
It probably should not be surprising, in this time of soaring medical costs and proliferating technology, that an intense debate has arisen over the concept of medical futility. Should doctors be doing all the things they are doing? In particular, should they be attempting treatments that have little likelihood of achieving the goals of medicine? What are the goals of medicine? Can we agree when medical treatment fails to achieve such goals? What should the physician do and not do under such circumstances? Exploring these issues has forced us to revisit the doctor-patient relationship and the relationship of the medical profession to society in a most fundamental way. Medical futility has both a quantitative and qualitative component. I maintain that medical futility is the unacceptable likelihood of achieving an effect that the patient has the capacity to appreciate as a benefit. Both emphasized terms are important. A patient is neither a collection of organs nor merely an individual with desires. Rather, a patient (from the word "to suffer") is a person who seeks the healing (meaning "to make whole") powers of the physician. The relationship between the two is central to the healing process and the goals of medicine. Medicine today has the capacity to achieve
\end{abstract}

L. J. Schneiderman $(\bowtie)$

Family and Preventive Medicine,

University of California San Diego School of Medicine,

0622, La Jolla, CA 92093-0622, USA

e-mail: 1js@ucsd.edu a multitude of effects, raising and lowering blood pressure, speeding, slowing, and even removing and replacing the heart, to name but a minuscule few. But none of these effects is a benefit unless the patient has at the very least the capacity to appreciate it. Sadly, in the futility debate wherein some critics have failed or refused to define medical futility an important area of medicine has in large part been neglected, not only in treatment decisions at the bedside, but in public discussions - comfort care - the physician's obligation to alleviate suffering, enhance well being and support the dignity of the patient in the last few days of life.

Keywords Medical futility · Comfort care · End-of-life · Rationing

\section{Defining Medical Futility and Improving End-of-Life Care}

Here is a scenario familiar to just about everyone engaged in critical care. A fifty-six-year-old woman is admitted to the ICU with dyspnea, extreme weakness, and cachexia from metastatic lung cancer. She is placed on a ventilator and vasopressor infusion to maintain her blood pressure. The health care team wants to write a Do Not Attempt Resuscitation (DNAR) order because, in their judgment, attempted CPR in the event of cardiac arrest-even if it did temporarily restore cardiac function-would be futile, since it would not fulfill a fundamental goal of their 
efforts: namely to restore her to a level of health that would permit her to survive outside the acute hospital setting. They believe the appropriate goal of treatment now is comfort care. However, her treatment wishes cannot be determined, and her family, in hopes of a miraculous cure, demand all possible life-sustaining treatments - including attempted CPR - if the patient undergoes a cardiac arrest.

Should the physicians follow the family's wishes to continue aggressive life-sustaining treatment including attempted CPR, or should the physicians refuse by invoking medical futility and seek to engage the family in emphasizing comfort care? What does it mean to invoke medical futility?

Although the concept of medical futility, to judge from ancient documents, is as old as medicine itself, the topic became particularly contentious over the last few decades. Some critics argued that medical futility could not be meaningfully defined, even calling for the term to be expunged from the medical lexicon (Truog et al. 1992). As one early critic acknowledged, however:

"Those who call for the abandonment of the concept have no substitute to offer. They persist in making decisions with, more or less, covert definitions. The common sense notion that a time does come for all of us when death or disability exceeds our medical powers cannot be denied. This means that some operative way of making a decision when 'enough is enough' is necessary. It is a mark of our mortality that we shall die. For each of us some determination of futility by any other name will become a reality" (Pellegrino 2005, 4).

\section{The Foundation and Components of Medical Futility}

It probably should not be surprising, in this time of soaring medical costs and proliferating technology, that an intense debate has arisen over the concept of medical futility. Should doctors be doing all the things they are doing? In particular, should they be attempting treatments that have little likelihood of achieving the goals of medicine? What are the goals of medicine? Can we agree when medical treatment fails to achieve such goals? What should the physician do and not do under such circumstances? Exploring these issues has forced us to revisit the doctor-patient relationship and the relationship of the medical profession to society in a most fundamental way.

If we look up the word "futility" in the Oxford English Dictionary, we learn that it means, "leaky, vain, failing of the desired end through intrinsic defect." What then is "failing of the desired end" in the case of medical futility?

\section{Quantitative and Qualitative Medical Futility}

Medical futility has both a quantitative and qualitative component. From the writings of the Hippocratic corpus we derive a quantitative notion: "Whenever the illness is too strong for the available remedies, the physician surely must not expect that it can be overcome by medicine ... To attempt futile treatment is to display an ignorance that is allied to madness" (Hippocratic Corpus in Reiser, Dyck, and Curran 1977).

There is also a qualitative aspect to medical futility that we can trace back to Plato's Republic where we find these statements: "For those whose lives are always in a state of inner sickness Asclepius [who was a legendary, indeed divine, physician] did not attempt to prescribe a regime to make their life a prolonged misery ... A life with preoccupation with illness and neglect of work is not worth living" (Plato 1981).

\section{Quantitative Futility}

To pursue first the quantitative aspect of medical futility, I draw your attention to the uncertainty inherent to the practice of medicine. Every medical student learns to "never say never." Philosophers such as David Hume and Karl Popper have pointed out that even though one sees B follow A a hundred or a thousand or even a million times, one can never be absolutely certain that the same thing will happen again (Popper 1961). ${ }^{1}$ Nevertheless, as reasonable

\footnotetext{
"With respect to the "idol of certainty," Popper states: "The old scientific ideal of episteme - of absolutely certain, demonstrable knowledge - has proved to be an idol. The demand for scientific objectivity makes it inevitable that every scientific statement must remain tentative forever. It may indeed be corroborated, but every corroboration is relative to other statements which, again, are tentative. Only in our subjective experiences of conviction, in our subjective faith, can we be 'absolutely certain"” (1961, 280; italics in the original).
} 
observers we inescapably begin to draw conclusions about likely causality at some point in our observations. Similarly, if B has never followed A after many events, at some point we begin to draw conclusions about the unlikelihood of B following A, although again we can never be absolutely certain. This kind of commonsense empirical reasoning forms the basis for our daily living activities. More particularly it is the basis for the clinical practice of medicine. To those who demand, "Are you absolutely certain?" the answer is always, "No." But the correct question is: How many times and to what degree do we have to fail before we agree to call a treatment futile? In medicine, as in our daily affairs, we act on the basis of empirical evidence. And so to overcome the paralysis of uncertainty that has forced physicians to pursue the most unlikely treatments, Nancy Jecker, Albert Jonsen, and I proposed what is nothing more than a commonsense definition of futility (Schneiderman et al. 1990).

Most of us probably would agree that if a treatment has not worked in the last 100 cases, almost certainly it is not going to work if it is tried again. (Statisticians can calculate that the upper limit of the $95 \%$ Confidence Interval is $3 \%$.) The experience of 100 cases is attainable in many areas of medicine. This proposal is not an "objective" or "value-free" definition, but rather one that seeks reasonable consensus where absolute certainty is impossible and therapeutic benefit is the goal. If we can agree to call this treatment futile, then the ordinary duty of the physician does not require offering it. $^{2}$

The medical community, or society at large, may prefer longer (or shorter) odds, but in the end we all will have to accept some empirical notion of medical futility or else throw all commonsense to the wind. In other words, we have to remember the denominator. If you truly want to make a case for attempting aggressive, lifesustaining, rib-cracking CPR on a patient who has a "one in a hundred chance" of working, you are claiming that it is appropriate to subject ninety-nine patients to an intervention that is painful, burdensome, and almost certainly useless in pursuit of one possible rare success. This violates medicine's duty to avoid unnecessary harm and the ethical duty of proportionality. Any physician who knowingly prescribed a drug with such a low therapeutic ratio and such severe side effects

\footnotetext{
${ }^{2}$ This argument is presented in more detail in Schneiderman and Jecker (2011).
}

would be (deservedly) vulnerable to the charge of medical malpractice.

Indeed, our proposed quantitative threshold is similar to that used in the statistical evaluation of clinical trials, which compares treatment observations against the null hypothesis (no difference) in light of the conclusion that these observations have a one in twenty chance of being nonsignificant $(p=0.05)$ or, more conservatively, a one in 100 chance of being nonsignificant $(p=0.01)$. One can never be certain, even in large-scale studies, that a treatment is beneficial (better than no treatment or an alternative treatment); therefore, one submits observations to the test of reasonableness. A good example of the application of our quantitative proposal is the publication of a Basic Life Support guideline based on empirical outcomes of out-of-hospital attempted CPR whose recommendation for terminating efforts followed the quantitative threshold we proposed (Sasson et al. 2008). The notion of reasonableness is accepted in another major sector of society where a person's life may be at stake: American courts of law. In the United States, a jury in a criminal trial may find a defendant guilty and subject to the death penalty if the evidence is persuasive not beyond all doubt, but beyond a reasonable doubt.

\section{Qualitative Futility}

I maintain that medical futility is the unacceptable likelihood of achieving an effect that the patient has the capacity to appreciate as a benefit. Both emphasized terms are important. A patient is neither a collection of organs nor merely an individual with desires. Rather, a patient (from the word "to suffer") is a person who seeks the healing (meaning "to make whole") powers of the physician. The relationship between the two is central to the healing process and the goals of medicine. Medicine today has the capacity to achieve a multitude of effects, raising and lowering blood pressure, speeding, slowing, and even removing and replacing the heart, to name but a minuscule few. But none of these effects is a benefit unless the patient has at the very least the capacity to appreciate it, a circumstance that is impossible if the patient is permanently unconscious.

My colleagues Albert Jonsen and Nancy Jecker and I also adopted the notion attributed by Plato to 
Asclepius that if the treatment fails to release the patient from being "preoccupied" with the illness and incapable of achieving any other life goal that treatment should also be regarded as futile. Hence, if the best outcome physicians can achieve to maintain survival requires keeping the patient perpetually confined to the Intensive Care Unit or the acute care hospital setting, that outcome should not be regarded as a success, but rather as a failure to achieve the goals of medicine. Such treatment, by our definition, is also futile (Schneiderman et al. 1990).

It is important that we make clear to society as well as to the profession that medicine has great powers, but not unlimited powers. The medical profession has important obligations, but not unlimited obligations. Failing to seek a precise definition of medical futility only leaves us in a state of ambiguity, which encourages the very abuses many people fear. Physicians should not be free to invoke medical futility unless they can justify it before their peers with good evidence-based data and before society with professional standards of practice. This requires that we examine the notion, not hide from it.

\section{Medical Futility: Seeking a Contemporary Definition}

A number of alternative definitions have been entered in the medical futility debate. One proposed definition holds that medical futility should depend upon the likelihood of achieving the patient's goals. In other words, the patient is entitled to receive any treatment and seek any outcome he or she wishes from the physician. This view has arisen out of the patient autonomy movement in reaction to abuses that took place in the previous era of strong physician paternalism. And although in many respects it is an admirable view, it is clearly flawed. Physicians are not obligated to yield, for example, to a patient's desire for mutilating or useless surgery. Indeed, surgeons make futility decisions every day simply by refusing requests to operate on a patient they deem "inoperable." If the patient's goal is to become a world champion bodybuilder with the aid of anabolic steroids, the physician is neither ethically obligated nor legally permitted to comply with the bodybuilder's request. These are but a few-there are many other-instances of limitations and prohibitions on the physician's duty to achieve the patient's goal. A particularly important limitation, in this era of Lifeas-a-TV-Movie of the Week, is that the physician does not owe the patient a miracle.

Another proposed definition of medical futility has to do with the unacceptable likelihood of prolonging life. Physicians, according to this notion, cannot declare a treatment futile as long as it can prolong life, even permanently unconscious life. Those who make this claim are probably unaware that the obligation of physicians to prolong life is not supported by the classical tradition of medicine (Amudsen 1978).

In ancient Greece and Rome, as expressed particularly through the Hippocratic writings, the physician's duties were described as assisting nature to restore health and alleviate suffering. Life and death were viewed as natural cycles. Indeed, the Hippocratic physician shunned claims of supernatural powers in order to avoid the taint of charlatanism. It was not until many centuries later in the late Middle Ages, when religion began to play a dominant role in Western Europe, and later in the seventeenth century, when scientists began to view science as a power to be exerted against nature, that the goal of prolonging life was introduced. It is important to keep in mind, however, that neither theologians, nor scientists, nor for that matter anyone else prior to the modern era could ever imagine life in the many forms it comes today, the many states between health and death that are the outcomes of modern medical treatments. The diagnosis of persistent vegetative state, to name just one condition, was not coined until 1972 (Jennett and Plum 1972). Thus, the claim that the goal of medicine is to preserve life has ambiguous meanings and dubious roots in the historical tradition of the profession.

Another proposal is that the definition of medical futility should be limited to the unacceptable likelihood of achieving any physiological effect on the body. According to this proposal, the physician cannot regard a treatment as futile as long as it can maintain the function of any part of the body, such as pumping blood by means of cardiac compression, moving air by means of mechanical ventilation, or eliminating wastes via dialysis, even if the patient is permanently unconscious or in the last moments of a terminal condition. In short, the instruments of technology are the focus of attention rather than the patient. This definition, physiologic futility, has been presented as a "value-neutral" definition (Truog et al. 1992). That 
there are those who seriously advocate it illustrates how much modern medicine has lost its way, how much it has become fragmented by subspecialties and technology. To specify narrow physiological objectives as the goals of medical practice is not "value neutral," but a value choice that is about as far from the patient-centered tradition of the medical profession as it is possible to be.

Furthermore, the focus on physiologic measures is also proving to be dangerous. For example, many diabetes specialists promoted strict control of blood glucose on the assumption that producing a physiological effect (lowering blood glucose) was equivalent to achieving a benefit for the patient (preventing complications and prolonging life). Well designed randomized control trials examining patient outcomes showed that strict control failed to reduce adverse cardiovascular outcomes and either increased or had no effect on mortality; moreover, it increased the risk for severe hypoglycemia in type 2 diabetes (Gerstein et al. 2008; Duckworth et al. 2009; Patel et al. 2008; Kelly et al. 2009; Wiener et al. 2008). Another example of effect-benefit confusion that proved harmful, even fatal, occurred when physicians imprudently began prescribing erythropoietin, a red cell growth factor, to raise blood levels to a "normal" range in anemic patients with cancer and chronic kidney disease. Once again, this physiological effect was assumed to be beneficial. Unfortunately, the treatment resulted in significantly more harms to patients, including stroke, heart attack, hospitalization, and death (Unger et al. 2010; Singh et al. 2006; Drucke et al. 2006).

\section{Exceptions and Cautions}

Although seeking to define and delineate the ethical implications of medical futility as precisely as possible, I acknowledge that medical practice calls upon us to recognize certain exceptions and cautions.

If the physician has the right to withhold a futile treatment, does this mean the physician enjoys the privilege of withholding discussion about such treatment? Certainly physicians do not describe to patients all the many tests and treatments they have no intention of pursuing. In my view, however, an important distinction should be made between treatment and information. Depending on the context and the patient's state of mind, patients may be entitled to information even though they are not entitled to treatments. Obviously, a physician need not discuss the remote possibility of brain surgery with every patient who has a headache. On the other hand, any patient in the Intensive Care Unit today, having watched television, is quite aware that attempted CPR is one of the possible treatment options. In this setting it seems to me quite clear that physicians owe it to the patient to discuss whether or not attempted CPR will be offered. Making a decision that a treatment is medically futile does not absolve the physician of the obligation to discuss and inform the patient/surrogate about what is going on in terms of the patient's condition, prognosis, and treatment options. But it would be a mistake to create an exchange that in effect has the physician advising the patient: "Attempting CPR would be of no use in treating your disease at this point. Do you want us to do it?" Such a communication sends a meaningless, even contradictory, message, which leads to confusion and distrust in the patient (Tomlinson and Brody 1990). Rather than assisting the patient in exercising autonomy, it actually deceives the patient and prevents the full exercise of autonomy.

What about the terminally ill patient who requests attempted CPR in hopes of surviving for one last visit from a distant loved one hastening to the bedside? Even though the physician is convinced that the intervention would have almost no chance of keeping the patient alive more than a day or so in the ICU, clearly the physician will want to make a compassionate exception to accommodate the short-term goal of the patient. It is important, however, to distinguish this compassionate act from an obligatory act. The physician can easily make a compassionate exception in the case of a severely burned patient or a patient with metastatic cancer whose request for treatment will result only in a brief prolongation of dying (a clear and limited goal and small exception to the physician's ordinary duty). But in the case of permanent vegetative state, obligating the physician to accede to a request for long-term life maintenance could lead to unaccounted decades of futile treatment. In contrast to those who raise fears about the erosion in value of the patient, giving the physician the opportunity to view each patient as a unique person in unique circumstances enhances the value of the patient. It encourages the use of appropriate medical measures rather than useless, thoughtless pursuit of 
inappropriate measures. A treatment may be futile. A patient is never futile.

\section{Beyond Futility to an Ethic of Care}

In ancient Greece, the futtilis was a religious vessel that had a wide top and a narrow bottom. This peculiar shape caused the vessel to tip over easily, which made it of no practical use for anything other than ceremonial occasions. The root of the term reminds us that words have a mythical power as well as a literal meaning. Is it not possible that unrealistic expectations and unreasonable demands for futile treatments, such as attempted CPR in a cancer patient with barely hours to live, may be expressions of deep ritualistic needs? These actions in our modern time have become almost religious ceremonies. Indeed, it is not too extreme to point out that in the past when patients sought a miracle they went to church and prayed to God; today they come to the hospital and demand it of the physician. Therefore, it is important to emphasize again: physicians are not obligated to produce a miracle. And, equally important, there are better actions that loved ones can seek and participate in that serve their needs to express love and veneration. This is called comfort care. Sadly, in the futility debate this important area has in large part been neglected, not only in treatment decisions at the bedside, but in public discussions - the physician's obligation to alleviate suffering, enhance well being, and support the dignity of the patient in the last few days of life (Schneiderman et al. 1994).

I believe it is important that the futility debate, both in public and at the bedside, be expanded beyond "pull the plug" decisions to include more attention to improving doctors' involvement in the details of end-of-life care, so that they do not say they have "nothing to offer" and walk away leaving the "nursing care" to nurses as seemingly beneath their attention. Patients and families who demand that "everything be done" may well be expressing a subtext: "Do not abandon me."

\section{The Heuristic Value of Defining Medical Futility}

There is an important heuristic value to the search for a clear definition of medical futility, whatever one emerges (Schneiderman and Jecker 1993). First of all, the futility debate has already resulted in more clarity of thinking, particularly in distinguishing medical futility from rationing (Jecker and Schneiderman 1992). Often these two concepts are entangled when expensive treatments are being administered to patients in the ICU; more often they are confused. For the sake of clarity I propose that medical futility signifies that a treatment offers no therapeutic benefit to a patient. Rationing specifically acknowledges that a treatment does offer a benefit, and the issue becomes how to distribute beneficial but limited resources fairly. To clarify the distinction further: futility decisions are made at the bedside of a specific patient, whereas rationing decisions, involving categories of patients or treatments or circumstances, inevitably should be made at a policy level in order to assure just distribution of resources.

Second, I believe that pursuing a clear-cut concept of medical futility will encourage a more aggressive search for precisely the kind of evidence-based information that our medical enthusiasm has caused us to overlook. I refer to the publication of clinical trials that report not only treatments that are successful, but also treatments that are unsuccessful. Both kinds of data are important to the practice of medicine; both provide guidelines for physician choice.

Third, empirical studies as well as consensus agreements form the basis for establishing standards of practice. These standards of practice should be declared openly as policies by medical centers and organizations of medicine for the information of the public and as guidelines to the courts. This last point is extremely important. Many patients and patients' families have been forced to endure and pay for inhumane, unwanted care either because of an individual physician's misguided notions of medical duty or because of hospital administrators' fears of inflammatory media coverage. Many physicians practice "defensive medicine," fearing that anything less than mindless continuation of aggressive treatments would make them legally vulnerable. As a consequence, they have given the courts little guidance but to "do everything possible," which, by default and against all common sense, becomes the standard of practice.

\section{Establishing Standards of Practice}

Futility policies, like all institutional policies, attempt to bridge the gap between the cultures of medicine 
and the law-doctors trying to say legal things, lawyers trying to say medical things. In the United States, at the federal level, the Uniform Health-Care Decisions Act states: "A health-care provider or institution may decline to comply with an individual instruction or health-care decision that requires medically ineffective health care or health care contrary to generally accepted health-care standards applicable to the health-care provider or institution" (Uniform Health-Care Decisions Act 1994, section 7, subsection f). It further clarifies that "medically ineffective" health care means "treatment which would not offer the patient any significant benefit" (Uniform Health-Care Decisions Act 1994, comment on section 7 , subsection $\mathrm{f}$ ). This statute has already been adopted by more than a half dozen states. In addition, professional societies - including the American Medical Association, the Society for Critical Care Medicine, and the American Thoracic Society-have published guidelines on medical futility.

Working groups of professionals and laypersons throughout the country have started to develop consensus-based futility hospital policies (Halevy and Brod 1996; Murphy and Barbour 1994; BANEC Nonbeneficial Treatment Working Group 1999). I led one such consensus conference. In order to keep itin that much-maligned phrase- - "fair and balanced," I asked a professor of law, Alexander Capron, who opposed the concept of medical futility, to be my cochair (Schneiderman and Capron 2000). There were seventy-four participants, consisting of physicians, attorneys, judges, and nurses, members of the clergy, social workers, and community representatives, representing ethics committee members from thirty-nine hospitals. The participants came from northern and southern California, from religious and secular institutions, from academic, managed care, and community hospitals, and from within and without the health care profession.

Contrary to the claim of some critics that the concept of futility could not be meaningfully defined, most of the participating hospitals independently crafted similar definitions of the term. During the proceedings I observed that physicians tended to seek specific and descriptive definitions of futile, inappropriate, or burdensome treatments. By contrast, lawyers and judges were more concerned about putting in place detailed procedures that protect vulnerable patients. I concluded that policies on futility should provide both specific definitions and a well described dispute resolution process that will bear scrutiny by outside, impartial observers.

When cases come to court, and on appeal to higher courts, it will be judges who decide whether professional judgment is in line with society's expectations. Judges will ask: Where does the medical profession stand? What standards does it profess? And, most tellingly, how does it behave?

Hospitals are likely to find the legal system willing (even eager) to defer to well defined and procedurally scrupulous processes for internal resolutions of futility disputes. Although courts are capable of providing due process protections, judges are largely unfamiliar with the complexity of medical treatment and are neither expected nor even able to follow up medical outcomes once they have entered judgment; it is the physicians seeking to cease futile treatment - and not the judges who are called upon to rule on the casewho have to live with the decision. For example, a judge who assigns a guardian and orders that a severely disabled child be kept alive rarely sees firsthand the long-term consequences of that decision, which remain a continuing vivid experience for the health professionals who must provide care for the child.

At the California conference neither the policies themselves nor the conference participants reached unanimous agreement on how to handle futility issues, and a follow-up survey 1 year after the conference revealed very few changes in the hospital futility policies. Does that mean that the questions, "Where does the medical profession stand? What standards does it profess?" cannot be answered? Is it necessary there be unanimous agreement in order to establish a professional standard of practice? Not at all, since the law does not demand unanimous agreement among professionals regarding issues that are matters of professional judgment. Differing standards are acceptable when some physicians hold one view and others another, provided each is held by at least a "respectable minority" and not just an individual practitioner.

Almost all of the futility policies agreed that physicians are not obligated to continue lifesustaining treatment of patients who have reliably been determined to be permanently unconscious. If this standard were recognized as the majority standard, one would still need to acknowledge that a 
"respectable minority" of hospitals have not adopted such an explicit policy statement.

In my view, however, these latter hospitals should consider the obligations and actions associated with their position. Is it a position or merely the absence of a position? Specifically, are these hospitals willing to accept the transfer of a permanently unconscious patient or others for whom another hospital has deemed further life-sustaining treatment futile? If so, disputes over end-of-life treatments could be resolved without requiring hospitals to go to court.

If the decision to forgo treatment has been reached by a process that is careful both in medical and procedural terms, including full discussion (where possible) with the patient or family, ethics committee review, and adequate aid to the patient and family in seeking care elsewhere, health care providers should not seek prior permission from the courts to carry out their professional duties. Indeed, there is substantial legal history in the United States to show that courts are more likely to support physicians who refrain from providing non-beneficial treatment and then defend their decisions as consistent with professional standards than when they seek advance permission to withhold such treatment. Judges do not want to make "medical decisions." In fact, they will rightly point out that they are being asked to agree to end lifesustaining treatment some time in the future when the patient's condition may have changed. If the rightness of that action is questioned after the fact, judges will want to know the answer to the third question, "How does the medical profession behave?" Thus, health care professionals need not only to develop policies but also to act in accordance with their policies. They also need to justify, through discussion and publication, their conduct in dealing with situations that have presented the issue of the limits of professional obligations when treatment does not yield results that would be regarded as beneficial by most patients and consistent with the goals of medicine (Schneiderman and Jecker 2011).

Back to the patient, the fifty-six-year-old woman admitted to the ICU. The health care team spent several days with the rest of the family in order to make a reasonable accommodation to their needs to grieve and come to terms with the patient's dying. The hospital has a policy that defines medically futile treatment and outlines steps to take in the event of a dispute between parties involved in decision-making.
The policy defines futile treatment as "any treatment that has no realistic chance of providing an effect that the patient would ever have the capacity to appreciate as a benefit, such as merely preserving the physiologic functions of a permanently unconscious patient, or has no realistic chance of achieving the medical goal of returning the patient to a level of health that permits survival outside the acute care setting of the medical center." The policy also states: "It should be emphasized that although a particular treatment may be futile, palliative or comfort care is never futile."

After mediation efforts failed to resolve the dispute, the family was given a date at which time anyone who wished could be present with the patient in a private setting when all life support and monitors would be withdrawn. This date gave them sufficient time to seek transfer of the patient or court intervention-which they chose not to do. Because the patient was ventilator- and vasopressor-dependent, the physicians could reasonably predict the patient would not linger. With the aid of benzodiazepines and morphine, she died peacefully in the presence of her family, who seemed relieved in the end that the physicians had assumed responsibility for this difficult decision.

Open Access This article is distributed under the terms of the Creative Commons Attribution Noncommercial License which permits any noncommercial use, distribution, and reproduction in any medium, provided the original author(s) and source are credited.

\section{References}

Amudsen, D.W. 1978. The physician's obligation to prolong life: A medical duty without classical roots. The Hastings Center Report 8(4): 23-30.

Bay Area Network of Ethics Committees (BANEC) Nonbeneficial Treatment Working Group. 1999. Nonbeneficial or futile medical treatment: Conflict resolution guidelines for the San Francisco Bay Area. The Western Journal of Medicine 170: 287-290.

Drucke, T.B., F. Locatelli, N. Clyne, K.U. Eckardt, I.C. Macougall, D. Tsakiris, CREATE Investigators, et al. 2006. Normalization of hemoglobin level in patients with chronic kidney disease and anemia. The New England Journal of Medicine 355: 2071-2084.

Duckworth, W., C. Abraira, T. Moritz, D. Reda, N. Emanuele, P.D. Reaven, VADT Investigators, et al. 2009. Glucose control and vascular complications in veterans with type 2 diabetes. The New England Journal of Medicine 360: 129-139. 
Gerstein, H.C., M.E. Miller, R.P. Byington, D.C. Goff Jr., J.T. Bigger, J.B. Buse, et al. 2008. Action to control cardiovascular risk in diabetes study group: Effects of intensive glucose lowering in type 2 diabetes. The New England Journal of Medicine 358: 2545-2559.

Halevy, A., and B.A. Brod. 1996. A multi-institution collaborative policy on medical futility. Journal of the American Medical Association 276: 571-574.

Hippocratic Corpus, The Art. 1977. In Ethics in medicine: Historical perspectives and contemporary concerns, ed. S. J. Reiser, A.J. Dyck, and W.J. Curran, 6-7. Cambridge: MIT Press.

Jecker, N.S., and L.J. Schneiderman. 1992. Futility and rationing. The American Journal of Medicine 92: 189-196.

Jennett, B., and F. Plum. 1972. Persistent vegetative state after brain damage: A syndrome in search of a name. Lancet 1 : 734-737.

Kelly, T.N., L.A. Bazzano, V.A. Fonseca, T.K. Theti, K. Reynolds, and J. He. 2009. Systematic review: Glucose control and cardiovascular disease in type 2 diabetes. Annals of Internal Medicine 151(6): 394-403.

Murphy, D.J., and E. Barbour. 1994. GUIDe (Guidelines for the Use of Intensive Care in Denver); A community effort to define futile and inappropriate care. New Horizons 2: 326331.

Patel, A., S. MacMahon, J. Chalmers, B. Neal, I. Billot, M. Woodward, ADVANCE Collaborative Group, et al. 2008. Intensive blood glucose control and vascular outcomes in patients with type 2 diabetes. The New England Journal of Medicine 358: 2560-2572.

Pellegrino, E.D. 2005. Decisions at the end of life - the abuse of the concept of futility. Practical Bioethics 1(3): 3-6.

Plato. 1981. In Republic, trans. G.M.A. Grube, 76-77. Indianapolis: Hackett Publishing Co.

Popper, K.R. 1961. The logic of scientific discovery. New York: Basic Books.

Sasson, C., A.L. Kellermann, and B.F. McNally. 2008. Prehospital termination of resuscitation in cases of refractory out-of-hospital cardiac arrest. Journal of the American Medical Association 300: 1432-1438.
Schneiderman, L.J., and A.M. Capron. 2000. How can hospital futility policies contribute to establishing standards of practice? Cambridge Quarterly of Healthcare Ethics 9: 524-531.

Schneiderman, L.J., and N.S. Jecker. 1993. Futility in practice. Archives of Internal Medicine 153: 437-441.

Schneiderman, L.J., and N.S. Jecker. 2011. Wrong medicine: Doctors, patients, and futile treatment, 2nd ed. Baltimore: Johns Hopkins University Press.

Schneiderman, L.J., N.S. Jecker, and A.R. Jonsen. 1990. Medical futility: Its meaning and ethical implications. Annals of Internal Medicine 1112: 949-954.

Schneiderman, L.J., K. Faber-Langendoen, and N.S. Jecker. 1994. Beyond futility to an ethic of care. The American Journal of Medicine 96: 110-114.

Singh, A.K., L. Szczech, K.L. Tang, H. Barnhart, S. Sapp, M. Wolfson, CHOIR Investigators, et al. 2006. Correction of anemia with epoetin alfa in chronic kidney diseases. The New England Journal of Medicine 355: 2085-2098.

Tomlinson, T., and H. Brody. 1990. Futility and the ethics of communication. Journal of the American Medical Association 264: 1276-1280.

Truog, R.D., A.S. Brett, and J. Frader. 1992. The problem with futility. The New England Journal of Medicine 326: 15601564.

Unger, E.F., A.M. Thompson, M.J.K. Blank, and R. Temple. 2010. Erythropoiesis-stimulating agents - time for a reevaluation. The New England Journal of Medicine 362: 1742-1743.

Uniform Health-Care Decisions Act. 1994. National Conference of Commissioners on Uniform State Laws, approved and recommended for enactment in all the states, Charleston, South Carolina, July 30-August 6, 1993. Available from National Conference of Commissioners on Uniform State Laws, 676 North St. Clair Street, Suite 1700, Chicago, IL 60611.

Wiener, R.S., D.C. Wiener, and R.J. Larson. 2008. Benefits and risks of tight glucose control in critically ill adults: A meta-analysis. Journal of the American Medical Association 300(8): 933-944. 